\title{
ИССЛЕДОВАНИЕ ПРЕДПОЧТЕНИЙ ПОТРЕБИТЕЛЕЙ ФИТНЕС-УСЛУГ СООБЩЕСТВА ФИТНЕС-КЛУБА
}

\author{
(c) 2021 Калиева Ольга Михайловна \\ доктор экономических наук \\ Оренбургский государственный университет, Россия, Оренбург \\ E-mail:kaf_mark@mail.ru \\ (ㄷ) 2021 Мантрова Марина Сергеевна \\ кандидат экономических наук \\ Оренбургский государственный университет, Россия, Оренбург \\ E-mail:mantrovams56@mail.ru \\ (c) 2021 Иневатова Ольга Александровна \\ кандидат экономических наук \\ Оренбургский государственный университет, Россия, Оренбург \\ E-mail: inevatova.olga@mail.ru \\ (c) 2021 Ватченко Дарья Анатольевна \\ Супервайзер ПАО «Совкомбанк», Россия, Оренбург \\ E-mail: darya.vatchenko@mail.ru
}

Приводятся результаты маркетингового исследования предпочтений потребителей фитнесуслуг сообщества фитнес-клуба в городе Оренбург. По результатам исследования предпочтений потребителей фитнес-услуг выделены критерии, на которые ориентируются потребители при выборе фитнес-клуба.

Ключевые слова: Фитнес-услуги, фитнес-клуб, фит-бизнес, клиенты, конкурентоспособность, опрос, инструменты маркетинга.

Актуальность исследования вопросов, связанных с маркетинговым анализом фитнесклубов на рынке фитнес-услуг, обусловлена высокими темпами развития и популяризации фитнес-услуг и, как следствие, проявлением со стороны общества все большего интереса к ним. В связи с этим, одним из приоритетных критериев успешного ведения фит-бизнеса и предоставления фитнес-услуг в условиях постоянно меняющейся рыночной конъюнктуры можно считать необходимость использования основных маркетинговых инструментов для изучения рынка услуг и регулирование с их помощью спроса и предложения.

Развитие фитнес-клубов в России началось еще в 90-х годах XX века, но активное развитие фитнес-клубов приходится на период с 2010 года по настоящее время. Маркетинг фитнес-услуг в современной отечественной науке рассматривается как новая концепция, инструментарий, технология, позволяющие фитнес-клубам разрабатывать стратегические направления развития фитнес-услуг. Стратегическое направление развития фитнес-клубов нацелено на привлечение массового потребителя. На региональных рынках вектор развития направлен на позиционирование (представление) фитнес-клубов в системе «эконом класса».

Маркетинг фитнес-услуг формируется на основе общей концепции маркетинга, так как современный рынок услуг предлагает отрасли физической культуры и спорта механизм, с помощью которого и осуществляется их коммерциализация.

Наряду с крупнейшими операторами фитнес-сетей на конец 2019 года - начало 2020 года такими как: World Class, Alex Fitness, Fitness House, OrangeFitness (согласно данным, представленным в журнале «Fitness Expert»), активно расширяющих сферу влияния на региональных рынках, и менее крупные операторы фитнесклубов официально объявили о планах масштабного расширения собственной сети.

По результатам исследований, представленных в РБК, за последние годы в России уровень проникновения фитнес-услуг в регионы соста- 
вил $2,5 \%$, в тоже время согласно статистическим данным рынок фитнес-услуг обладает большим потенциалом роста. Явление роста рынка фитнес-услуг происходит по нескольким причинам: естественный рост населения, мировая пропаганда здорового образа жизни, приобщение к спорту старшего поколения, фитнес-центры как центры досуга и свободного времяпрепровождения и поддержание рабочего тонуса [3].

В настоящий момент на рынке фитнес-услуг в г. Оренбург функционирует около 100 фитнесцентров, среди которых 25 - с наличием залов для проведения групповых тренировок, в 5 фитнес-клубах представлены бассейн и сауны.

Проведенное исследование в виде опроса в социальной сети «Вконтакте» среди подписчиков сообщества фитнес-клуба «Х» в г. Оренбург с целью выявления основных критериев выбора данного фитнес-клуба, а также предпочтений потребителей, далее клиентов, позволило выявить основные конкурентные преимущества фитнес-клуба на рынке фитнес-услуг.

Рассматриваемый фитнес-клуб «Х» располагается в западной части города, в густонаселенном районе, рядом расположены как многоэтажные дома, так и частный сектор. Площадь фитнес-клуба «Х» составляет 1200 м², фитнес-клуб имеет разделение по зонам: зона единоборств, зона кроссфита, кардио зона, велнес зона, бассейн, детская комната, зона отдыха (фитнес-бар). Месторасположение фитнес-клуба обусловлено потенциально большим клиентопотоком, так как расположен он в крупном торгово-развлекательном центре города.

В опросе принимали участие 500 респондентов, выборка сформирована в возрастной категории от 23 до 65 лет. Результаты опроса представлены на рис. 1 А-И.

По результатам данного опроса можно сделать вывод, что 69,4\% опрошенных занимаются спортом, из них, преимущественно мужчины. Большая часть клиентов фитнес-клуба «Х» проживает в районе расположения фитнес-клуба, также они и являются активными пользователями услуг данного фитнес-клуба. Что касается цен на услуги, то большая часть клиентов при покупке абонемента руководствуется выбором абонемента, который будет предложен им по скидочной цене. Большое значение для выбора фитнес-клуба является хороший отзыв, рекомендация о нем. Так в результате опроса можно наблюдать, что 76,8\% респондентов проголосовали за вариант «по рекомендации знакомых».

На вопрос «Вы занимаетесь самостоятель-

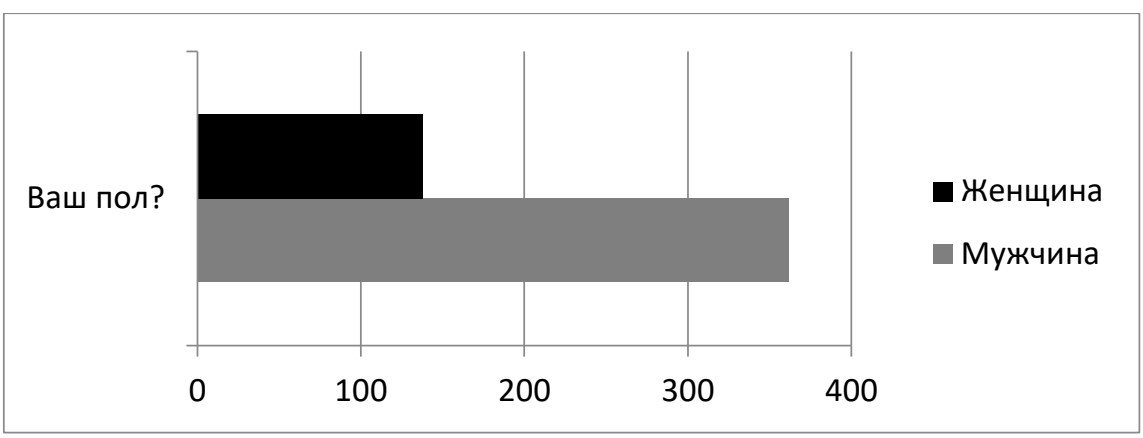

А) Результаты по ответам на вопрос: «Ваш пол»

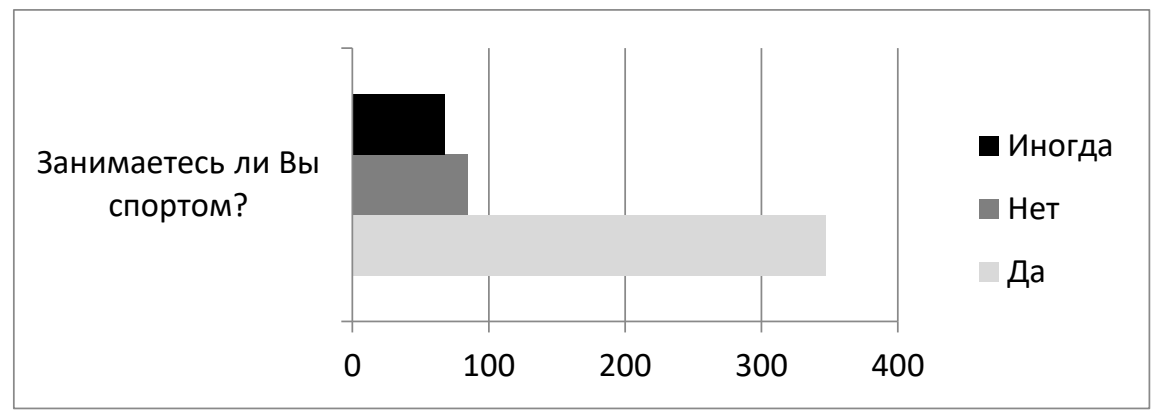

Б) Результаты по ответам на вопрос: «Занимаетесь ли Вы спортом?» 
В каком районе города Вы проживаете?

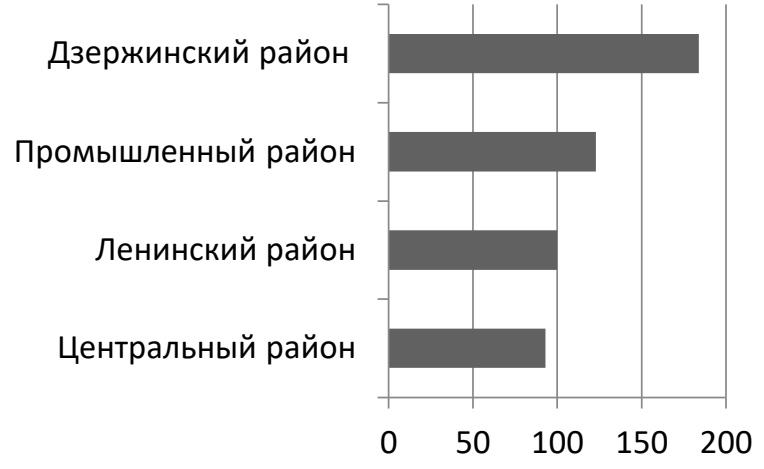

В) Результаты по ответам на вопрос: «В каком районе города Вы проживаете?»

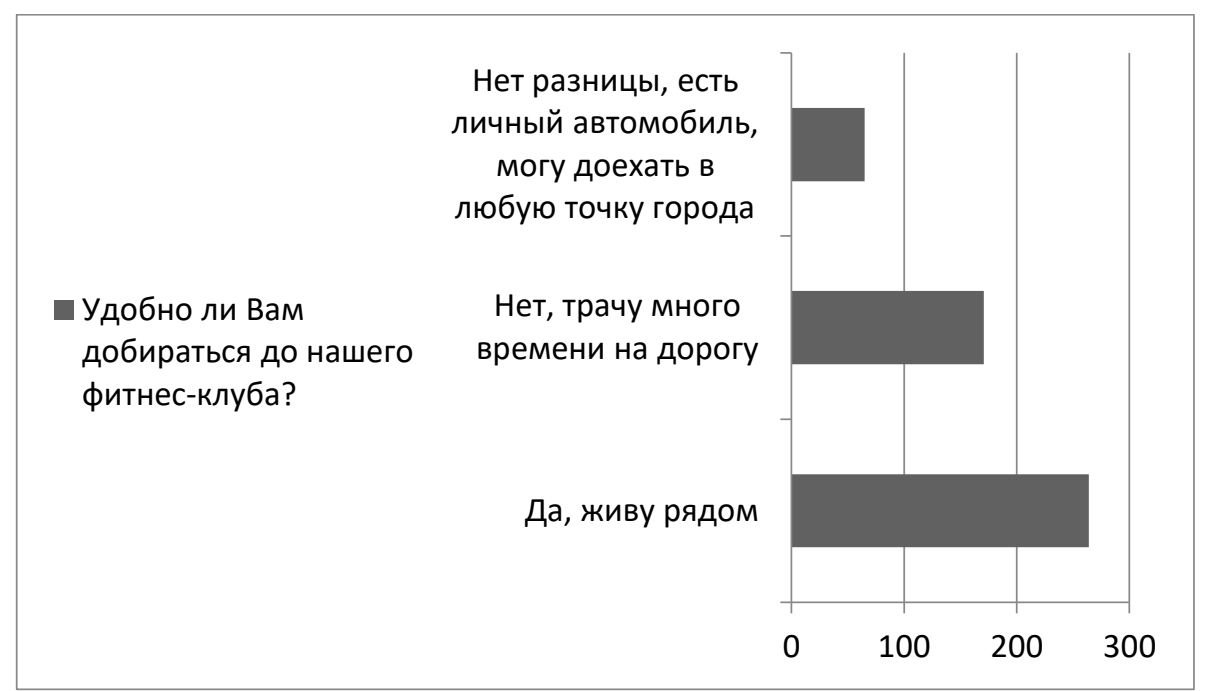

П) Результаты по ответам на вопрос: «Удобно ли Вам добираться до нашего фитнес-клуба?»

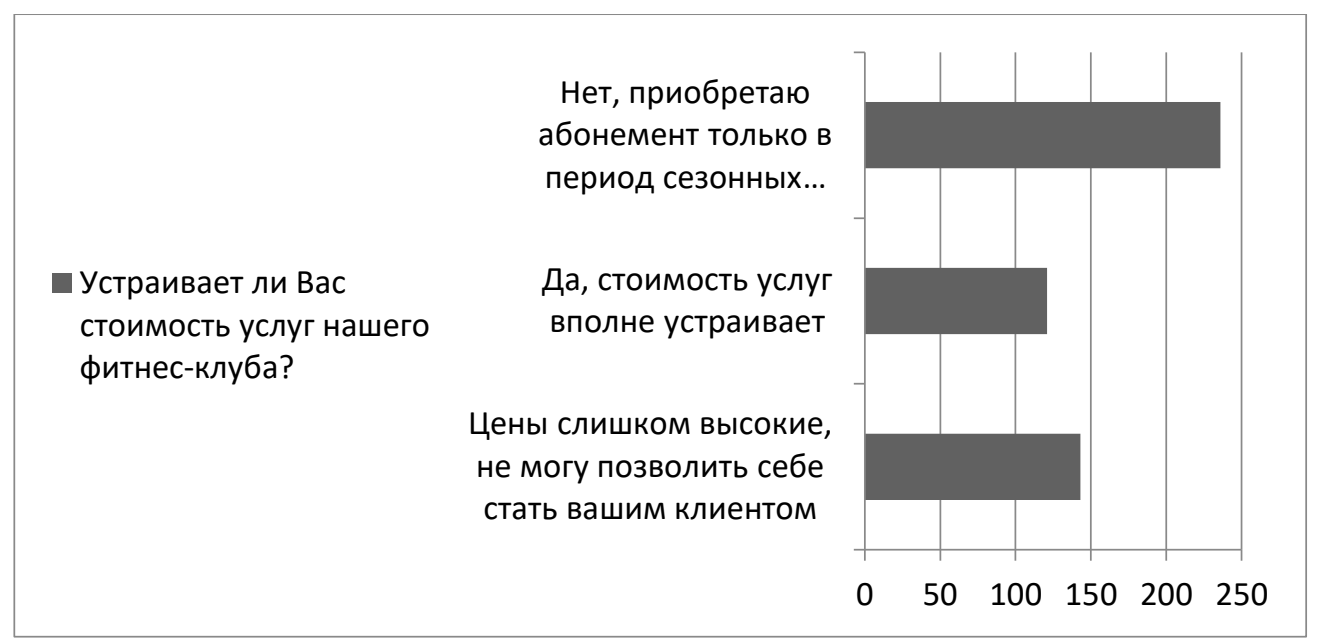

Д) Результаты по ответам на вопрос: «Устраивает ли Вас стоимость услуг нашего фитнес-клуба?» 


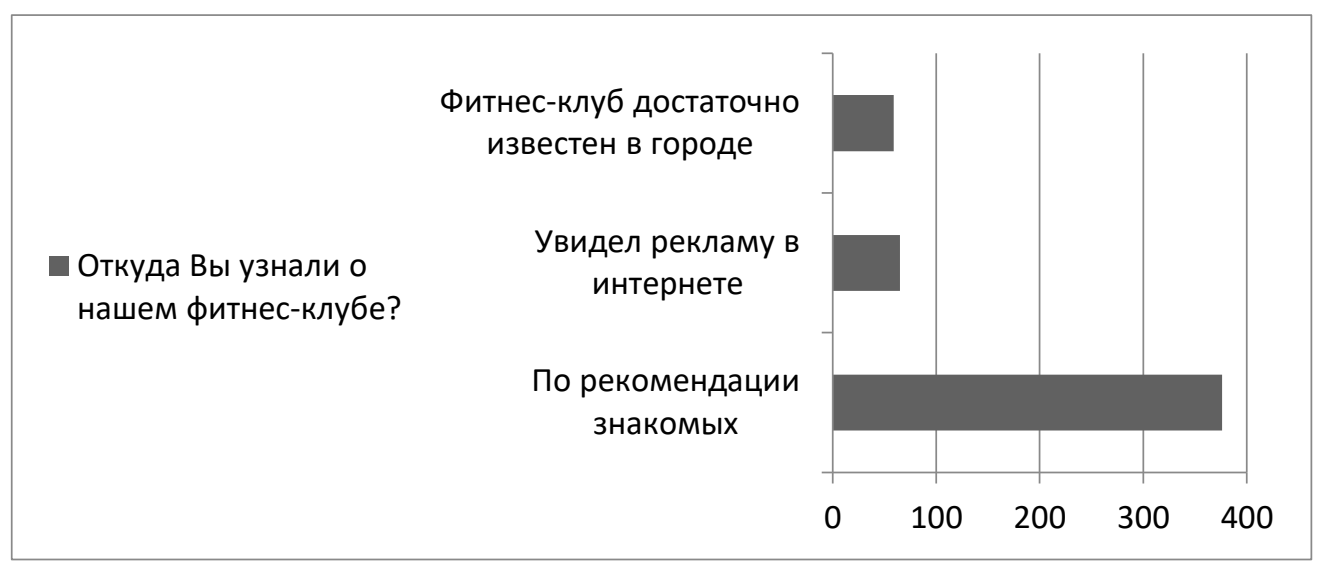

Е) Результаты по ответам на вопрос: «Откуда Вы узнали о нашем фитнес-клубе?»

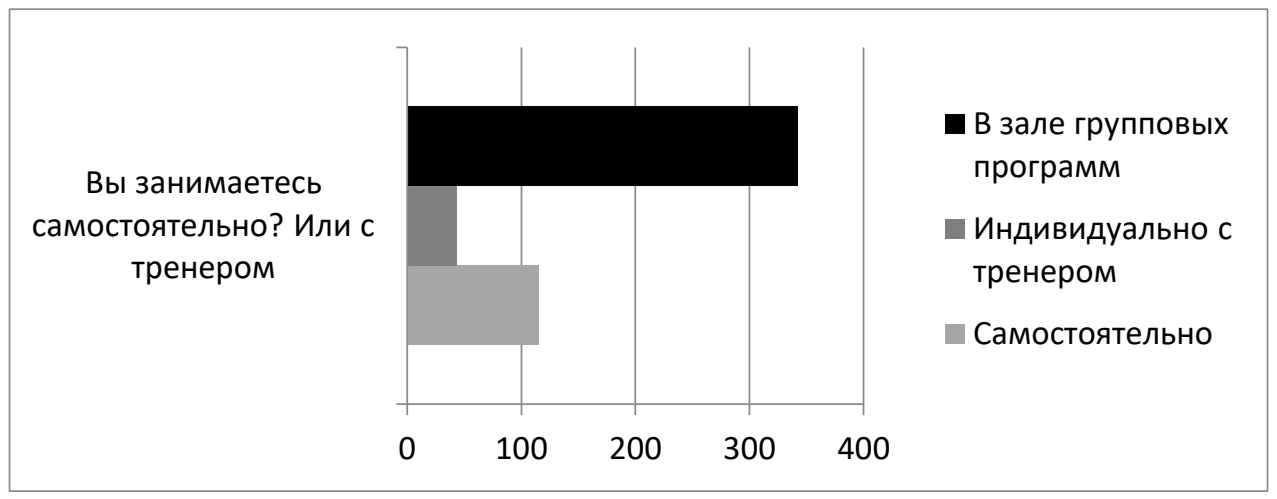

Ж) Результаты по ответам на вопрос: «Вы занимаетесь самостоятельно? Или с тренером?»

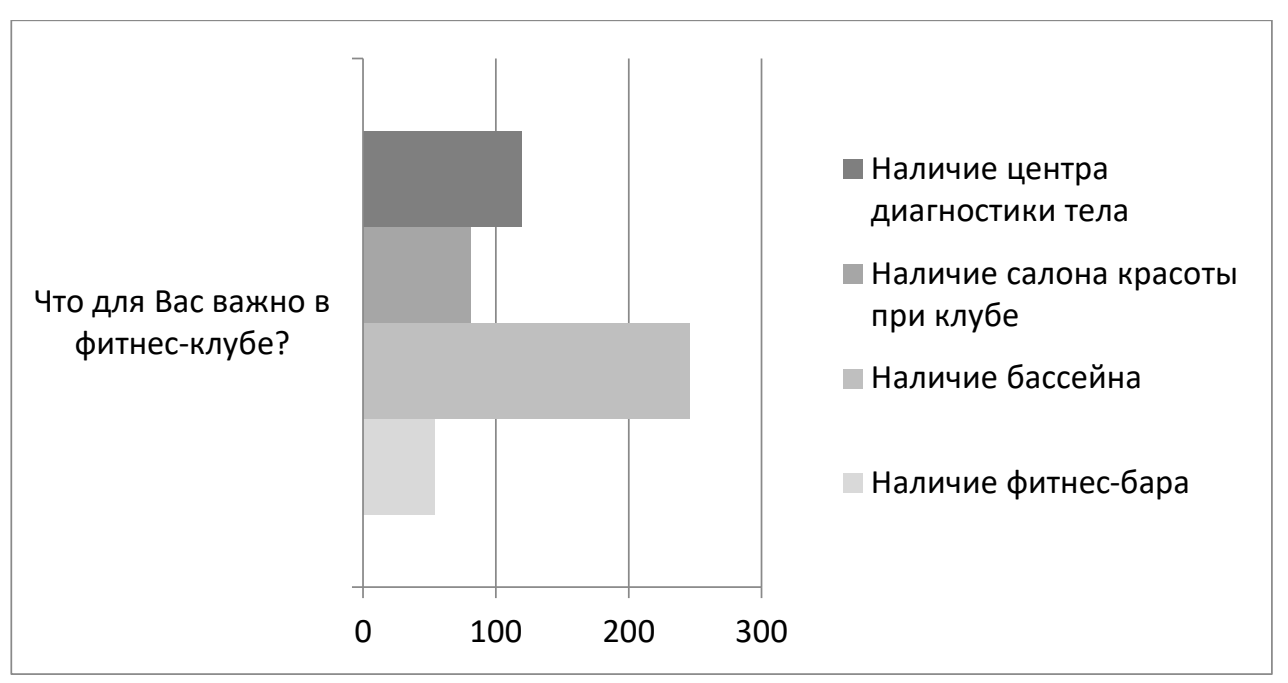

3) Результаты по ответам на вопрос: «Что для Вас важно в фитнес-клубе?» 


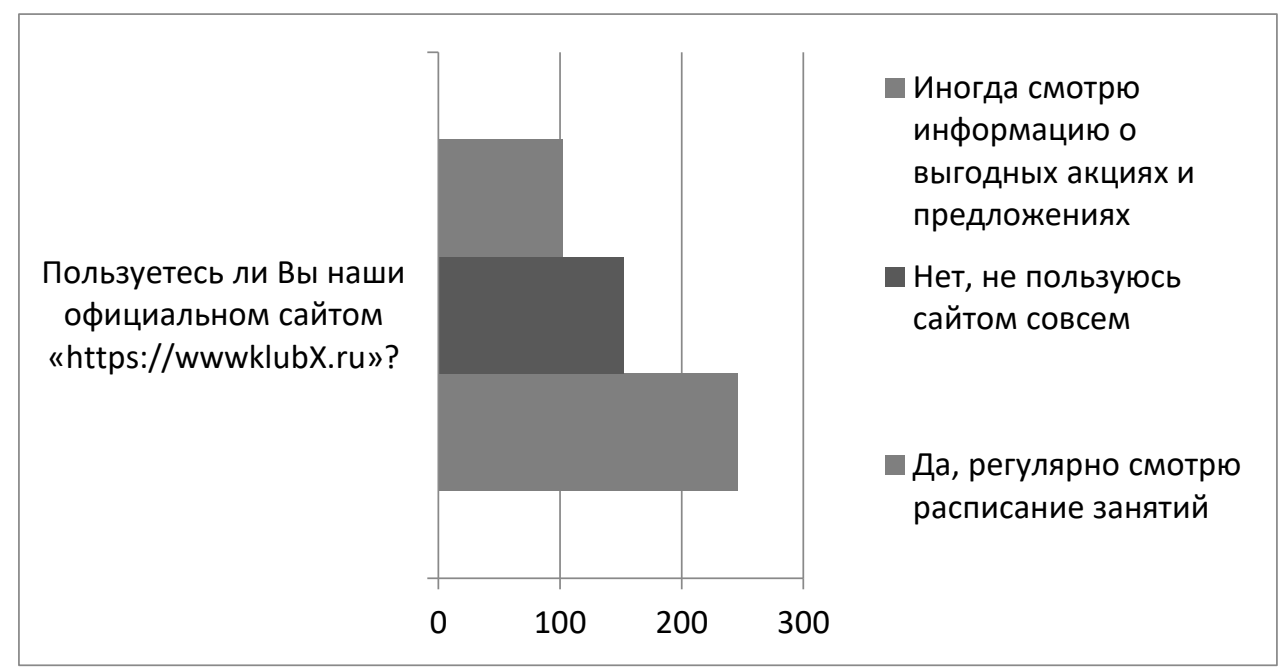

И) Результаты по ответам на вопрос: «Пользуетесь ли Вы нашим официальным сайтом

https://wwwklubX.ru?»

Pис. 1. Результаты опроса в социальной сети «Вконтакте» среди подписчиков фитнес-клуба «Х»

но или с тренером» $66 \%$ респондентов указали, что занимаются в зале групповых программ, что свидетельствует о том, что клиенты либо не владеют информацией о наличии персонального тренера в фитнес-клубе, либо не могут себе позволить приобрести данную услугу ввиду высокой стоимости. Примерно половина опрошенных указали, что в фитнес-клубе они хотели бы иметь возможность пользования бассейном. Около 248 участников опроса пользуются официальным сайтом фитнес-клуба для просмотра расписания, при этом 150 человек не пользуются сайтом совсем. Поэтому необходимо повышать значимость пользования официальным сайтом, так как с помощью него можно информировать клиентов о новинках, акциях и пр.

По результатам исследования предпочтений клиентов можно выделить основные критерии, на которые ориентируются потребители при выборе фитнес-клуба, к которым относятся:

1. Месторасположение. На рынке фитнесуслуг в г. Оренбурге наблюдается следующая тенденция расположения фитнес-центров:

- крупные фитнес-клубы, занимающие большую площадь, располагаются как отдельно стоящие здания, имеют большую площадь парковочных мест;

- фитнес-клубы меньшего масштаба занимают территорию в крупных торговых центрах;

- фитнес-клубы, имеющие небольшой клиентопоток, занимают малую площадь и, как правило, арендуют первые или нулевые этажи в жилых домах, а также помещения совместно с другими организациями в здании.

Согласимся и порекомендуем для [2] фитнесклубов осуществлять выбор месторасположения для проведения занятий поблизости от мест расположения потенциальных и реальных потребителей с учетом прогноза клиентопотока.

2. Стоимость фитнес-услуг. Также весомым конкурентным преимуществом фитнес-клуба является цена. От установленных цен зависит количество клиентов, денежный оборот, доходность и рентабельность клуба. [1], что на практике, рекомендуется применять «плавающие» цены, вместо фиксированных, неизменных. Ценовой диапазон может изменяться в зависимости от:

- полноты приобретаемого пакета услуг в фитнес-центре;

- вида тренировок (групповой тренинг или индивидуальный);

- сезон приобретения абонемента. От смены времени года зависит посещаемость клиентов фитнес-клуба. Высокая посещаемость выявляется в весенний период, чуть ниже в осенний и зимний. Летом количество клиентов в фитнесклубе значительно снижается;

- времени суток действия абонемента. Рассмотрим график посещения фитнес-клуба «Х» в зависимости от дней недели и времени суток, рисунок 2.

Рассмотрев график посещения клиентов фитнес-клуба «Х» в течение недели, можно сде- 


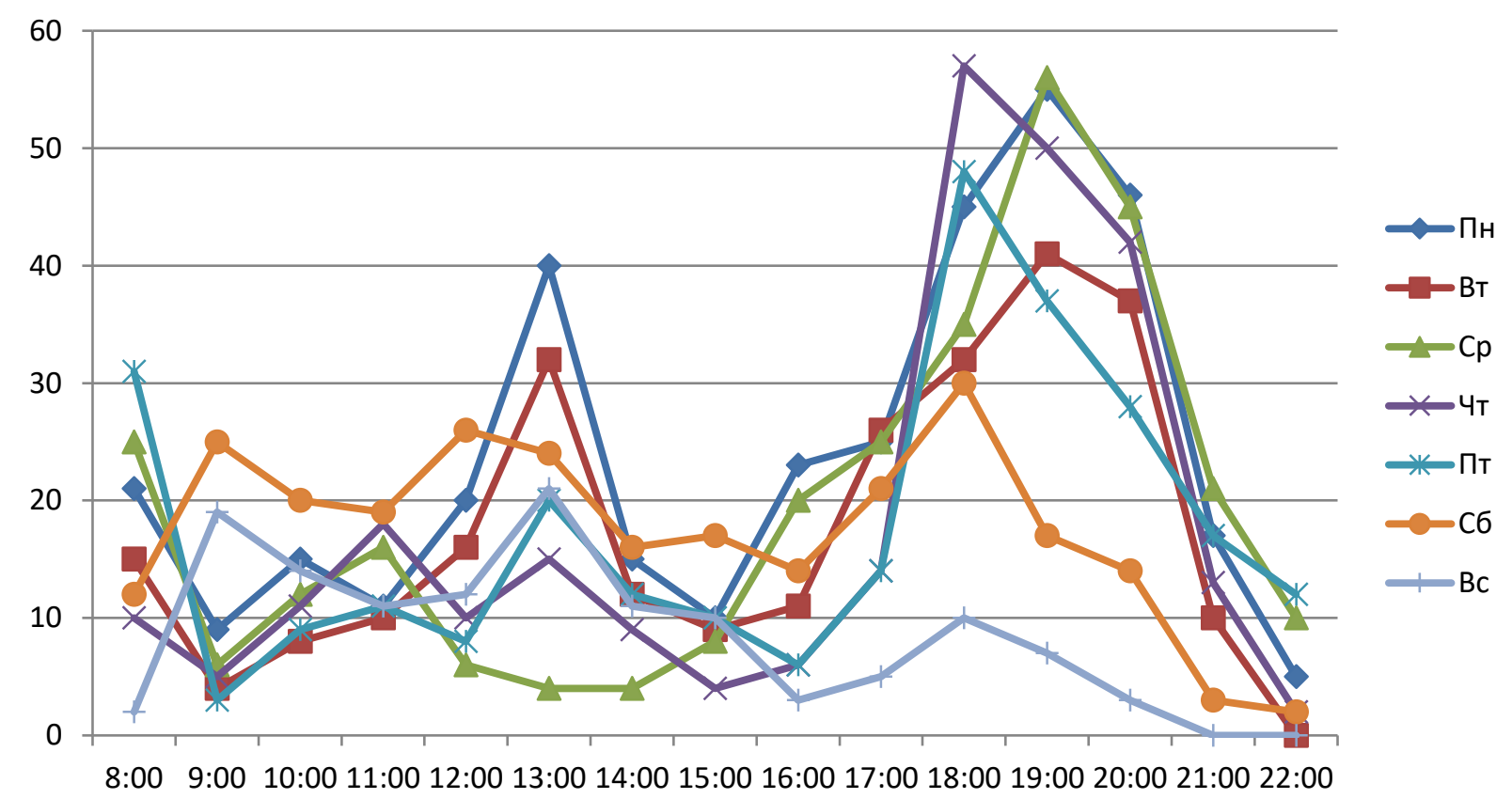

Puc. 2. График посещения фитнес-клуба «Х» в течение недели (составлено на основе выгрузки из отчета посещений по клубным картам)

лать вывод, что спрос на услуги является непостоянным, так как многие клиенты стремятся посещать клуб в конкретные дни недели и в определённое время. Высокий спрос наблюдается, в основном утром в 8:00, в обеденное время 13:00 и в конце рабочего дня - 18:00.

Фитнес-центру для максимизации собственной прибыли следует предлагать дополнительные услуги, а не только абонементы на занятия. K предоставляемым дополнительным услугам в фитнес-клубах, относят: персональные тренировки, диагностирование тела, консультации врача-диетолога, косметологические консультации и процедуры, услуги студии загара. Предоставление дополнительных услуг дает возможность фитнес-клубам существенно увеличить денежный оборот за счет увеличения клиетопотока [2].

3. Статус и привлекательность фитнесклуба. Для узнаваемости бренда и привлечения клиентов фитнес-клубы используют рекламу в интернете. Для наглядного представления информации о фитнес-клубе можно обратится к его официальному сайту в сети интернет. Переходя на сайт, можно увидеть часы работы клуба, посмотреть расписание, ознакомиться с тренерским составом, а так же получить консультацию специалиста оставив заявку. На фоне сайта иногда используют интерьер фитнес-клуба, чтобы клиент частично ознакомился с помещением.
Использование анимационной рекламы на сайте может создавать неудобства при просмотре сайта клуба. Также можно оставить заявку на входящий звонок от специалиста и получении консультации.

Наиболее важными показателями, используемыми для продвижения официального сайта, по нашему мнению, являются: полнота предоставляемой информации о фитнес-клубе и оперативность обновления информации. Данные показатели помогут потенциальному клиенту узнать о фитнес-клубе, получить необходимую или недостающую информацию. Подача информации, её обновление и дизайн несут важную нагрузку для сайта, так как привлекают пользователей и акцентируют внимание на уникальных предложениях.

4. Спектр оказываемых услуг. Для примера рассмотрим в сравнении наличие дополнительных услуг в крупных фитнес-клубах г. Оренбурга (таблица 1).

Можно отметить, что некоторые позиции пересекаются, что дает клиенту право дополнительного выбора. По перечисленным дополнительным услугам лидирует фитнес-клуб «Х». Из этого следует, что у фитнес-центра «Х» есть большой потенциал для развития и ряд преимуществ перед конкурентами.

5. Уровень квалификации тренерского состава и остальных сотрудников фитнес-клуба. 
Таблица 1. Дополнительные услуги в крупных фитнес-центрах г. Оренбурга

\begin{tabular}{|l|l|l|}
\hline \multicolumn{1}{|c|}{ Фитнес-клуб «Х» } & \multicolumn{1}{|c|}{ Фитнес-клуб «Y» } & \multicolumn{1}{|c|}{ Фитнес-клуб «Z» } \\
\hline Авторские уроки & Бассейн & Кросс-фитнес \\
\hline Мини-группы & Единоборства & Чайная комната \\
\hline Массажный кабинет & Молодетский клуб & Молодетский клуб \\
\hline Солярий & Массаж & Фитнес-кафе \\
\hline Магазин спортивных товаров & Физическое диагностирование тела & $\begin{array}{l}\text { Центр диагностики и восстанов- } \\
\text { ления }\end{array}$ \\
\hline Хаммам & Хаммам & - \\
\hline Спортивные секции & - & - \\
\hline Мастер-классы & - & - \\
\hline Коррекция питания & - & - \\
\hline Детские секции & - & - \\
\hline Фитнес-бар & - & - \\
\hline Душ Шарко & - & - \\
\hline Бассейн & - & - \\
\hline Аренда полотенец & - & - \\
\hline
\end{tabular}

Проблемы коммуникационного плана, а в частности проблема в выстраивании коммуникаций между посетителями фитнес-клуба и персоналом устраняются за счет повышения квалификации персонала, организационными способами и не требуют большого денежного вложения. Высокое качество предоставляемых фитнес-услуг позволит фитнес-клубам сформировать лояльность клиента и положительный имидж.

Подводя итог, отметим, что на сегодняшний день отрасль фитнес-услуг развивается за счет инструментов маркетинга, которыми являются:

- прогноз состояния и развития целевых рынков фитнес-услуг;

- изучение изменения потребностей всех целевых аудиторий фитнес-услуг;

- формирование гибкого ценообразования на услуги фитнес-клубов;
- совершенствование работы фитнесцентров с потребителями фитнес- услуг;

- создание коммуникаций, связей с общественностью и реклама.

Без вышеуказанных инструментов маркетинга, особенно в области продвижения фитнес-услуг, фитнес-центры не смогут максимизировать собственную прибыль, достигать планируемого уровня эффективности собственной деятельности на рынке. Поэтому предприятиям, функционирующим в данном рыночном сегменте необходимо на постоянной основе осуществлять планирование, анализ, контроль результатов собственной деятельности, деятельности конкурентов и проводить мониторинг организации собственной работы и ситуации на рынке.

\section{Библиографический список}

1. Асомчук А.А. Продвижение фитнес-услуг/Бюллетень науки и практики № 6(июнь). - 2016. - С.6-12.

2. Барбарук А. И. Маркетинговое исследование рынка фитнес-услугв России и Санкт-Петербурге/И.А. Красюк// Экономические науки.-2018.- С.28-31.

3. Официальный сайт РБК (РосБизнесКонсалдтинг) [Электронный ресурс].- Оренбург. 2020.- URL: https:// www.rbc.ru/(датаобращения 16.12.2020) 